 aring

\section{Shared Next Generation ILSs and Academic Library Consortia: Trends, Opportunities and Challenges}

\author{
Guoying Liu and Ping Fu
}

\begin{abstract}
:
Next generation Integrated Library Systems (ILSs) have been maturing and adopted by more and more academic libraries. Many academic libraries have joined a consortium to collaboratively move towards a shared next generation ILS that sustains a deeper collaboration. Has this been a trend for academic libraries to share the new system in consortia? This article examines the adoption of the leading products in next generation ILSs to reveal the trend. Two case studies are conducted on A) a pioneer consortial adopter and B) a newly formed partnership on shared next generation ILSs, for further investigations on the impact on consortial members, the challenges the new shared system may cause, and the opportunities it brings to academic library consortia and their members.
\end{abstract}

To cite this article:

Liu, G., \& Fu, P. (2018). Shared next generation ILSs and academic library consortia:

Trends, opportunities and challenges. International Journal of Librarianship, 3(2), 53-71.

To submit your article to this journal:

Go to http://ojs.calaijol.org/index.php/ijol/about/submissions 


\title{
Shared Next Generation ILSs and Academic Library Consortia: Trends, Opportunities and Challenges ${ }^{1}$
}

\author{
Guoying Liu, University of Windsor, Windsor, ON, Canada \\ Ping Fu, Central Washington University, Ellensburg, WA, USA
}

\begin{abstract}
Next generation Integrated Library Systems (ILSs) have been maturing and adopted by more and more academic libraries. Many academic libraries have joined a consortium to collaboratively move towards a shared next generation ILS that sustains a deeper collaboration. Has this been a trend for academic libraries to share the new system in consortia? This article examines the adoption of the leading products in next generation ILSs to reveal the trend. Two case studies are conducted on A) a pioneer consortial adopter and B) a newly formed partnership on shared next generation ILSs, for further investigations on the impact on consortial members, the challenges the new shared system may cause, and the opportunities it brings to academic library consortia and their members.
\end{abstract}

Keywords: Integrated Library Systems, Next Generation Integrated Library Systems, Library Services Platforms, Consortia, Academic Libraries, Collaboration

\section{INTRODUCTION}

\section{Library Consortia}

Library consortia are groups of two or more libraries that "partner to coordinate activities, share resources and combine expertise" (Rosa and Storey, 2016, p93). Partnership, or collaboration, is the main purpose of a consortium. Other names have been used for collaborating libraries in library literature as well, such as cooperatives, networks, collectives, and alliances (Horton, 2015). In this article, we adopt the term consortium and/or consortia for libraries that collaborate with each other to achieve common goals.

Library consortia have existed for over a century. Their scope, type and size are varied. The collaboration of libraries can be at the local, regional, national or international level. Some consortia serve exclusively one specific type of libraries, such as academic or

\footnotetext{
${ }^{1}$ Early version presented at the $9^{\text {th }}$ Shanghai International Library Forum and published in the conference proceedings as follows: Liu, G. and Fu, P. (2018) Shared Next Generation ILSs and Academic Library Consortia: Trends, Opportunities and Challenges. In Proceedings of Shanghai International Library Forum (SILF), October 18-19, 2018, Shanghai, China, pp. 309-323.
} 
public, while others include multiple types. Many of them started as academic only and later expanded to include public, special and other types of libraries. (Bostick, 2001; Horton, 2015). The size of a library consortium could be as huge as Online Computer Library Center (OCLC) which had over 22,000 members in 2012 (Horton, 2015), or be very small like Keio-Waseda Consortium which only consists of two members (ProQuest, 2018).

Library consortia's activities are varied as well. A 2006-2007 American Library Association (ALA) national survey on consortia revealed that the most common services and activities within consortia are communication, resource sharing, professional development, consulting and technical assistance and cooperative purchasing. Other less common activities include automation, networking and other technology services, etc. (Davis, 2007). A more recent examination by Rosa and Storey (2016) found that American libraries all face the challenges of funding, evolving role of the library, and the changing nature of scholarly communication. They are "more connected than they have ever been in the history of library and information science" (p85). Resource sharing, cooperative acquisitions and e-content licensing, as well as shared online catalog are among the most used services in library consortia.

\section{Next Generation ILSs}

Library automation has experienced several phases of development since its beginning in 1960s (Borgman, 1997). Earliest library systems were created to provide a specific function or resolve a particular issue, such as circulating materials or creating catalog cards. The following efforts are to integrate these separate pieces of software into one system, the Integrated Library System (ILS). A standard traditional ILS normally contains the modules of cataloging, circulation, serials management and open public access catalog (OPAC). This type of systems were designed for print resources management. With the advances of information technology, library automation products based on server/client emerged on the market around mid-1990s. In the meantime, electronic resources started to grow. However the main functional modules of ILSs remain unchanged. A number of add-on library systems were developed to address various library needs beyond what a traditional ILS can meet, such as link resolvers, electronic resource management systems, digital asset management, institutional repositories and discovery interfaces. (Breeding, 2013; Liu, 2015)

The year of 2011 witnesses the start of a new cycle of library automation - the emerging of next generation ILS. Meanwhile, Breeding (2011b) proposed a concept of Library Services Platform (LSP) to differentiate the next generation ILS from the traditional ILS. In this paper, we use next generation ILSs for the new emerging systems to emphasize its integration feature and avoid any confusion it may cause because both LSPs and next generation ILSs have been used often in library literature and libraries. The next generation ILSs are able to manage all forms of library collections including print, electronic and digital resources. They can introduce pertinent workflows according to the type of resources (print or electronic), the call of services (local or remote) and the acquisitions models (purchasing or licensing) (Breeding, 2011b; Liu, 2015). The new systems shall also take advantage of cloud computing and other latest technologies and architectures (Grant, 2012). 
Alma from Ex Libris and WorldShare Management Services (WMS) from OCLC are the two earliest products that have been developed from ground up in this area (Wilson, 2012). Since their launch in 2012, both products have been maturing. By the end of 2016, Alma has been adopted in over 800 libraries and WMS in over 400 libraries. Other two products active in current market are Sierra by Innovative Interfaces and FOLIO, an open source initiative supported by EBSCO (Breeding, 2016; Breeding, 2017b). Sierra took a different approach from Alma and WMS. It reused many Millennium system functions rather than creating original innovations (Grant, 2012). Sierra has been installed in over 600 libraries since it was introduced in 2011. FOLIO entered the market in 2016 and is currently under development (Breeding, 2017b).

\section{Academic Library Consortia and Library Automation}

"The growth of information technology has increased the importance of consortia" (Kopp, 1998, p.7). Library automation started around 1960s when most of the early academic library consortia were formed (Borgman, 1997; Kopp, 1998). Libraries were motivated to collaboratively develop systems and share automation techniques to computerize manual, labor-intensive operations to improve overall efficiency. Automating large-scale technical processing was the primary concern of large consortia at the time (Bostick, 2001; Kopp, 1998).

In 1970s and 1980s, computer hardware became less expensive and the automated library systems emerged. ILS was born combining automated back room operations (Borgman, 1997). It became unnecessary for libraries to cooperate to acquire automated systems. Libraries tended to focus on the development and implementation of their local ILSs rather than consortial activities. As a result, the growth of consortia slowed down to some degree (Kopp, 1998).

By the late 1980s to 1990s, most libraries had "achieved certain levels of local systems and networking sophistication" (Kopp, 1998, p.14). Combining with fiscal, political and other factors, academic library consortia re-flourished with an emphasis on acquiring and providing access to electronic resources via the Internet as well as sharing physical resources (Kopp, 1998; Potter, 1997).

From the 1990s into 2000s, many libraries had their own separate standalone ILSs in house. However, the development of cloud computing pushed libraries to reconsider the remotely hosted library systems supported by vendors and consortia (Machovec, 2014). Next generation ILSs were introduced. In his 2011 automation market report, Breeding (2011a) predicted that more libraries would consider adopting the cloud based, multi-tenant automation products as well as participating in shared automation systems in consortia to save cost. Libraries have become "willing to look at much more profound and fundamentally ground-breaking collaborations" and demand automation vendors to offer collaborative functionality to support library success (Horton, 2012a, p.130). In 2011, Orbis Cascade Alliance (OCA) decided to create a "truly shared integrated library system" for all of its 37 member institutions (Horton, 2012b, para. 3.). This would allow for deeper collaboration among its members, including unified collections and shared technical services. According to an OCLC survey (2013), in response to what the most valuable aspect of joining a consortium is, $12 \%$ of U.S. library consortia leaders chose a shared ILS, 
which is on par with e-content purchasing and third to professional networking (30\%) and cost savings $(23 \%)$.

In his regular column in the Collaborative Librarianship, Ayre (2015) illustrated all compelling features for library consortia to collaborate deeper by adopting shared next generation ILSs. It was stated that all sharing activities and services would be streamlined and simplified, including user access and staff workflow. A shared system would save individual member libraries not only on hardware, software and licenses costs but also personnel for system administration, cataloging, collection development, and even selections and acquisitions.

Would it be a new direction for academic libraries to collaboratively select and manage shared next generation ILSs? This article aims to analyze the trends, impacts, opportunities and challenges for academic libraries in the shared next generation ILSs.

\section{LITERATURE REVIEW}

A great deal of research articles and presentations have addressed the topic of next generation ILSs and consortia in library literature. Although the concept of next generation ILSs is still relatively new in the profession.

OCA is a pioneer of library consortia in the adoption of shared next generation ILSs. It has served as a model for many other academic library consortia (Helmer, et al., 2012). From system selection and migration to its impact on the library operations and various functional areas, librarians and other researchers from OCA have contributed a number of papers sharing their experiences and insights of a shared next-generation ILS in a large academic library consortium.

Cornish, Jost and Arch (2013) detailed the process for selecting a shared next generation ILS for all 37 OCA members, including the foundational steps, Request for Information (RFI), teams and processes of Request for Proposal (RFP), and negotiation with suppliers.

Steve Shadle at the University of Washington Libraries presented the migration experience to the next generation ILS and a single shared catalog in OCA, including the motivation for the consortial migration, the implementation process and lessons they have learned (Shadle and Davis, 2016). Stewart and Morrison (2016) from the same institution further examined the consortial migration and its impact on acquisitions workflows and collection building in the shared system. Shared ILS migration is also investigated from a technical services perspective by the staff from another OCA library (Zhu and Spidal, 2015).

The consortially shared ILS has also changed the library operations in OCA (McKiel and Dooley, 2014). Librarians from pioneering libraries in the OCA looked at the acquisitions policies and workflows in the new system (Spring, Drake and Romaine, 2014). The challenges and opportunities for collaboration on acquisitions have also been discussed (Spring et al., 2015). Romaine and Wang (2017) analyzed the serials and electronic resources management (ERM) functionality and workflows in a shared ILS. The discovery end accompanied with a next generation ILS and its impact on library database usage is 
included in the literature as well (Evelhoch, 2016). In addition, Fu (2017) investigated the impact of next generation ILSs on the U.S. library consortia.

Literature sees newer articles coming from other consortia who have selected or are interested in a shared next generation ILS. Deng, Sotelo and Culbertson (2018) at the University of California, San Diego, conducted literature review and a survey on cataloging consortial collections in preparation for the upcoming migration to the next generation ILS in the consortium. Five trends have been identified, including the outlook that local library catalog is not dead yet, as well as several approaches for consortial cataloging.

Cote and Ostergaard (2017) from the Treasure State Academic and Information Services (TRAILS) Consortium examined the role of electronic resources librarians in the process of consortial migration to next generation ILSs. They concluded that the North American Serials Interest Group (NASIG)'s Core Competencies for electronic resources librarians "provide a framework from which to approach" the next generation ILS implementation (p. 228).

Consortia from other regions or countries, such as Hong Kong, Canada and South Africa, are also interested in this topic. Eight universities in Hong Kong in the Joint University Librarians Advisory Committee (JULAC) started a new adventure in 2013 aiming to collaborate on a shared next generation ILS. After several years of planning, consultation and RFP process, JULAC selected Alma and Primo in 2016 and went live with the shared system in July 2017. Major challenges they encountered include merging bibliographic records, user account authentication, user-initiated borrowing, data migration, and multilingual authority control, etc. Opportunities are also presented to participating libraries, such as shared cataloging, shared collection development, shared workflow, expertise and training (Chan and Lam, 2016; Lam, 2017).

In 2016 Library Technology Conference, Anika Ervin-Ward and Amy Greenberg (2016a) presented the Ontario Council of University Libraries (OCUL) Collaborative Futures (CF) project. The OCUL CF project aims to collaboratively adopt a shared next generation ILS. The OCUL Case Study section in this article will detail its goals, approaches and status along with the discussion on challenges and opportunities of this provincial project in Canada.

In South Africa, Mfengu (2014) interviewed senior library management teams in four institutions of Cape Library Consortium and found that these institutions were willing to adopt the next generation ILS in the next five years. They were in a process of preparing for this move in terms of staff and infrastructure change. The member institutions would like to take advantage of consortial approach and still function individually.

Machovec (2014) listed the following challenges facing consortial solutions of next generation ILSs: selecting a system, determining costs, defining levels of collaboration, security, scalability and performance of the solution, and the integration with other library applications. Although Alma is the dominating product selected by home institutions of the authors of the related literature, Machovec (2014) did name a couple of examples other than Alma, such as the Private Academic Libraries of Indiana (PALNI) who migrated to WMS and MOBIUS consortium who have upgraded to Sierra. 
Rarely does research in the literature target the trend of academic library consortial adoption of the next generation ILSs. More investigations from various perspectives and environments would provide further expositions on the impacts, challenges and opportunities of such a substantial joint adventure for academic libraries around the world.

\section{METHODS}

To identify the trend for academic libraries to adopt a shared ILS within a consortium, the authors of this article collected and analyzed the number of academic library consortia that have moved to a shared next generation ILS in the past few years.

Marshall Breeding's annual product reports are a good source for the adoption number of next generation ILSs. The library automation statistics tracked on the Library Technology Guides (https://librarytechnology.org/) are another source of data for this article.

However, these sources do not provide separate information on academic consortia. The press releases on individual products have been collected and reviewed for the analysis. In the next generation ILS market, only Alma, WMS and Sierra have sufficient installations in libraries to be meaningful for this study (Breeding, 2017a). Although WMS has gained sizable market in academic libraries, it "has had few selections by large academic libraries or consortia" (Breeding, 2017b, $2^{\text {nd }}$ para. under Academic Libraries/OCLC). There is little information on academic libraries adoption of WMS either on library literature or on the Internet. It lacks literature on Sierra as well. The Press Center of Innovative Interfaces (https://www.iii.com/press-center/) contains news releases on the selection and migration of Sierra by libraries but the data are available only from 2016. It appears the number of press releases is not complete for all library adoptions of Sierra.

Good news is that it looks like all press releases on Alma adoption since 2011 are preserved and accessible via the News and Events on the Ex Libris website (http://www.exlibrisgroup.com/press-releases/). The number of total adoptions of Alma on the press releases also agrees with what has been presented in Marshall Breeding's reports and statistics (Breeding, 2018a; Breeding, 2018c). In addition, the number matches what is described in the internal document of the Ex Libris' response to OCUL CF RFP for a next generation ILS in January 2018 (one of the authors of this article sit on the OCUL CF RFP Requirements and Evaluation Working Group). Therefore, data collected via the press releases on Alma adoption on the Ex Libris website are quite reliable.

This article reviews all available data on the adoption of Sierra (from January 5, 2016 to April 9, 2018) and Alma (from January 6, 2011 to April 3, 2018) on the Internet. The analysis mainly relies on Alma's adoption data during 2011-2018 with a particular focus on the consortial adoption. All adoption numbers from the websites of Ex Libris, Innovative Interfaces, and Library Technology Guides are collected and verified during April 1-15, 2018.

In addition to the analysis on the adoption number, two cases, OCA and OCUL, under different stages of consortial adoption of a next generation ILS are studied to provide in-depth analysis on the impact of shared next generation ILSs on consortia and their 
members as well as the challenges and opportunities to them. OCA is the pioneer in this area in the world, who have gone live with Alma for a couple of year; whereas OCUL is among the first consortia in Canada aiming for a completely shared next generation ILS, and is currently selecting a shared system.

\section{ADOPTION OF NEXT GENERATION ILSS IN ACADEMIC LIBRARY CONSORTIA}

\section{Data from Library Technology Guides by Marshall Breeding}

Table 1 lists the number of consortia respondents and the total number of all respondents to the annual International Survey of Library Automation in 2012-2017. The respondents come from all types of libraries primarily in English speaking countries (Breeding, 2018d). The data include a variety of library automation products, such as traditional ILSs and next generation ILSs.

Some comments in the 2017 survey state they are part of a consortial shared system, but responded as individual libraries (Breeding, 2018b).

Table 1 shows that the number of consortia respondents from 2012 to 2017. Although it appears that during 2012-2017, the number of consortia respondents to the annual library automation perceptions survey goes up gradually (see Figure 1), the percentage of consortia respondents among the total number of respondents (both consortial and individual respondents) does not support such trend (see Figure 2).

\begin{tabular}{|l|l|l|}
\hline Year & Consortia & Total \\
\hline $\mathbf{2 0 1 2}$ & 97 & 3,032 \\
\hline $\mathbf{2 0 1 3}$ & 91 & 3,003 \\
\hline $\mathbf{2 0 1 4}$ & 95 & 3,143 \\
\hline $\mathbf{2 0 1 5}$ & 127 & 3,459 \\
\hline $\mathbf{2 0 1 6}$ & 116 & 4,042 \\
\hline $\mathbf{2 0 1 7}$ & 142 & 3,992 \\
\hline
\end{tabular}

Table 1. Number of Respondents (Consortia and Total)

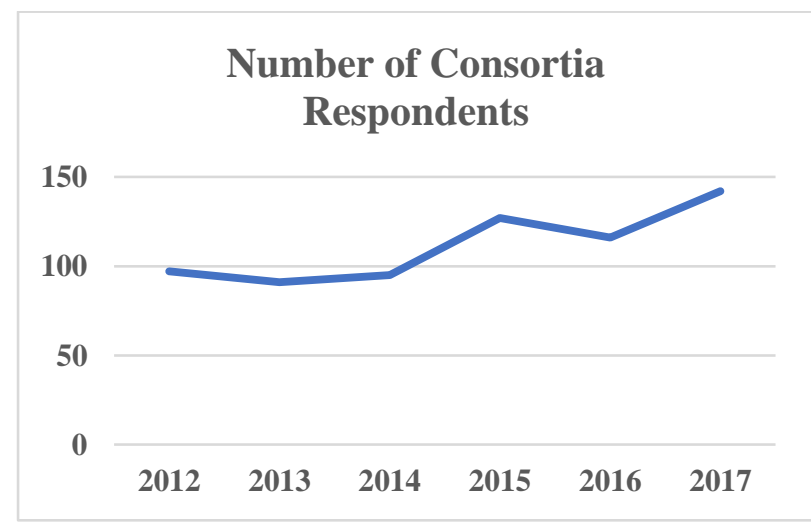

Figure 1. Number of Consortia Respondents 


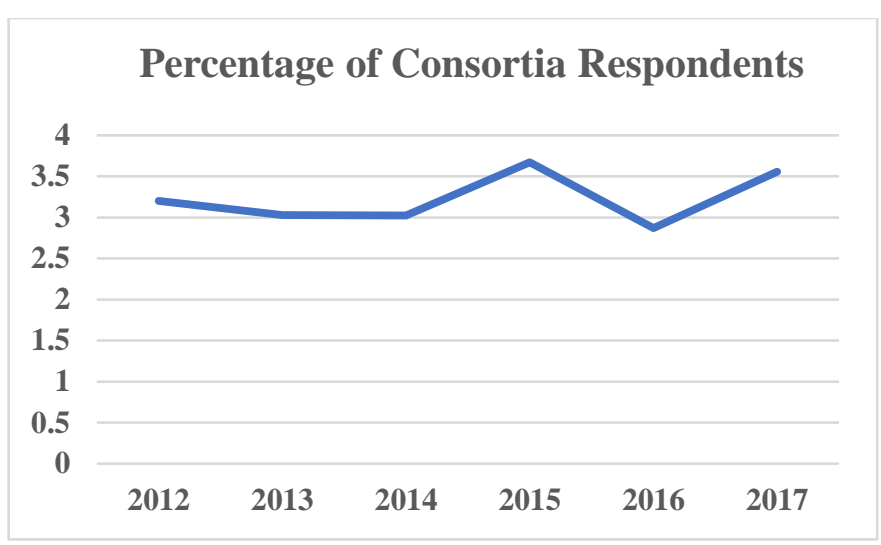

Figure 2. The Percentage of Consortial Respondents

Based on the Integrated System Turnover maintained by Marshall Breeding (2018a), Figure 3 illustrates the number of academic libraries who have selected Alma, Sierra or WMS in 2010-2017. Alma appears starting to lead the market after 2015.

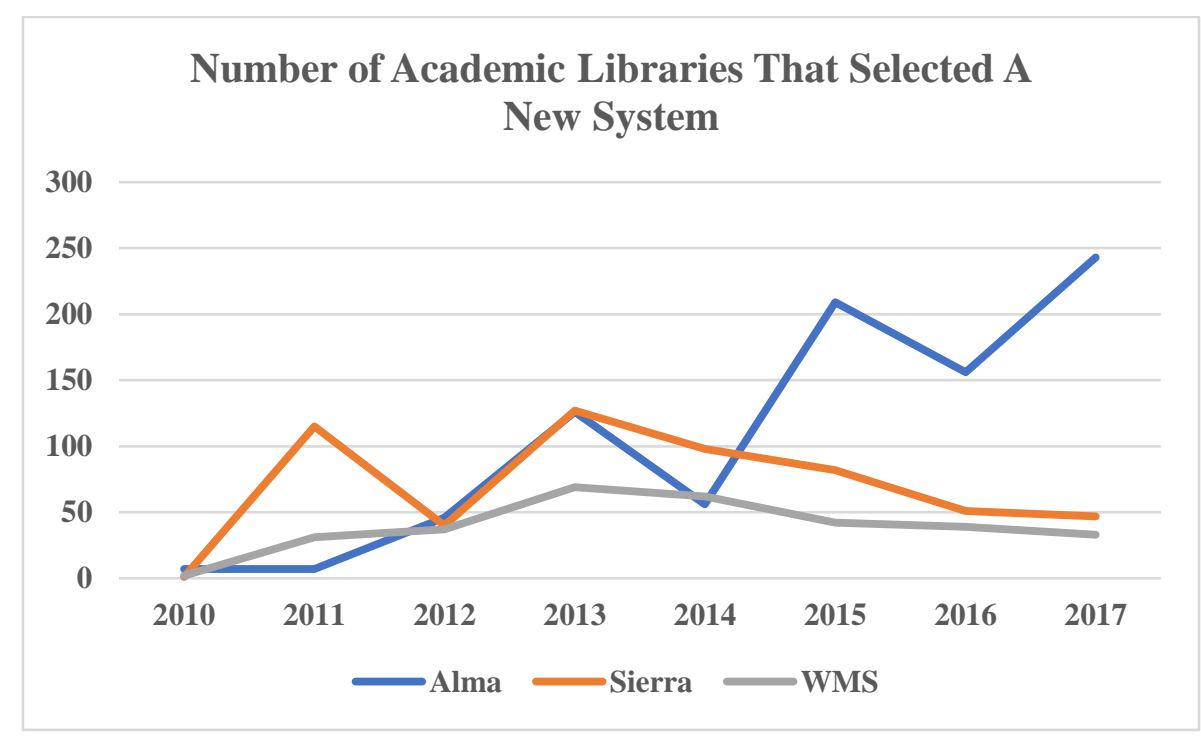

Figure 3. Number of Academic Libraries That Acquired a New ILS/LSP 2010-2017)

\section{Press Releases for Alma Adoption}

The Press Releases from News \& Events on the website of Ex Libris (http://www.exlibrisgroup.com/press-releases/) were examined for the product Alma since its beginning, January 6, 2011 when the first announcement was released on Alma.

Table 2 displays the number of consortia who have selected Alma in 2011-2017. 


\begin{tabular}{|l|l|}
\hline Year & Number of Consortia Selected Alma \\
\hline $\mathbf{2 0 1 1}$ & 2 \\
\hline $\mathbf{2 0 1 2}$ & 2 \\
\hline $\mathbf{2 0 1 3}$ & 3 \\
\hline $\mathbf{2 0 1 4}$ & 7 \\
\hline $\mathbf{2 0 1 5}$ & 7 \\
\hline $\mathbf{2 0 1 6}$ & 11 \\
\hline $\mathbf{2 0 1 7}$ & 10 \\
\hline
\end{tabular}

Table 2. Number of Consortia Selected Alma

Figure 4 shows the continual growing number of consortia that have selected Alma as their shared next generation ILSs in the past few years. It indicates that academic libraries are more likely working together to select a shared next generation ILS.

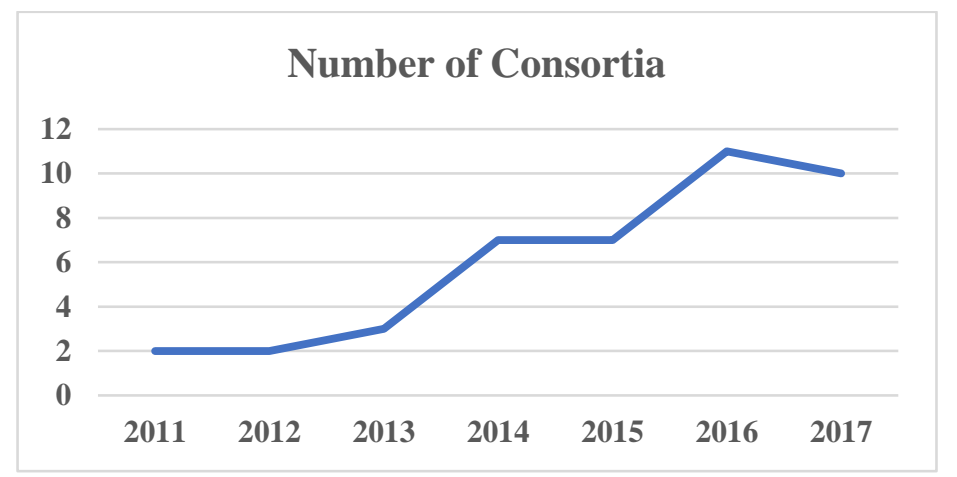

Figure 4. Number of Consortia That Have Selected Alma

The press releases on the year of 2018 have also been reviewed carefully. Till April 3, 2018, five individual institutions and three consortia have selected Alma in the year of 2018. The three consortia include two Japanese universities, and seven university members of Michigan Shared System Alliance, and 64 campuses in the State University of New York. There are 78 academic libraries have selected Alma in total in 2018, and among them 73 are part of a consortium who selected the product together. That means among Alma adopters, about 94\% academic libraries have joined a consortium for a shared next generation ILS in 2018.

\section{CASE STUDIES}

\section{Case Study 1 - OCA: Experience, Impacts, Opportunities and Challenges}

OCA is a library consortium of 39 academic libraries in Oregon, Washington, and Idaho, serving faculty and the equivalent of more than 280,000 full-time students. From January 2013 to January 2015, the then 37 OCA libraries completed migration from three different locally hosted ILSs and four different discovery platforms to a shared next generation ILS, 
Alma, and a single discovery platform Primo. The Alliance and its member libraries took a multi-year process for exploring systems options, creating policies and standards for data cleaning, planning and organizing the migration, and creating collaborative programs and teams after migration. The Alliance created numerous working groups to perform collaborative tasks at each stage of the project.

Through analyzing the OCA programs, documents, reports published on the OCA websites, conference presentations authored by the OCA members and delivered at the Ex Libris Users of North America conferences, in-person interview, and journal articles authored and published by librarians and professionals of the OCA member libraries, we find, particularly, from a member institution's perspective, the shared next generation ILS has made significant impacts and generated numerous opportunities and challenges on almost all aspects, particularly on the following areas of the OCA and its member institutions:

\section{Resource Sharing}

According to the OCA Alliance-Wide Summit Borrowing 2017 and Summit Lending 2017, there were a total of 312,874 borrowing requests and a total of 261,372 lending requests received among its 39 institutions in 2017 . The fill rate was $80 \%$ and $93 \%$ respectively. Our study shows that the new shared system has greatly improved users' access to information through resources sharing in the OCA libraries. Compared to the previous OCA's resource sharing system called Summit, the new Summit seamlessly integrated consortial borrowing and lending systems and interlibrary loan system with the shared ILS Alma and front end system Primo. The new Summit allows patrons to easily search and request library materials owned by consortial members or other libraries outside the consortium through a single Primo user interface. Every member library can follow the same procedures and policies to achieve efficiency and predictability.

During an in-person interview, Erin Bledsoe, a senior circulation staff at Central Washington University, who participated in the OCA Alliance Resource Sharing Implementation Team, responded that the new shared ILS brought significant benefits to both patron and library staff. She emphasized that the new shared ILS "allows the user to access all of the library and consortial holdings; physical, electronic and digital, by searching in one search box." Patrons "no longer have to interface with third party vendor (i.e. WorldCat)." The new system provides "real-time availability, not requestability." The shared best practices also "allow for similar experiences throughout consortium." Erin Bledsoe added that "detailed audit trail can help staff troubleshoot problems. General messages and notes can be used to indicate damage, multiple parts." She recognized that shared creation of documentation and best practices are helpful for staff training and professional development.

\section{Discovery and User Experience}

Our study shows the new shared next generation ILS provides a single high-quality, webbased discovery and delivery platform for all consortium member institutions. It enables discovery of resources, regardless of format or resource type, in local or consortial collections and beyond. It enables member institutions to customize the search experience by controlling for preferred formats and locations and implementing individual 
institution's needs and brand components. The new Primo interface has become a central portal for access to unique local information resources, including digital collections from member libraries. It provides users with a web-based portal for assistance in conducting searches on the internet, evaluating the quality of information resources, learning how to use various databases and linking them to library resources throughout the consortium. It also provides users with the advantages of a union catalog, such as consistent query interpretation across multiple libraries with quick response time across a large number of library records. It supports efficient computerized library services, including up to the minute information about the availability of library materials, circulation information, journal collection status, and computerized checkout. It offers access to an array of online user-initiated services, such as the ability to review materials checked-out, renew books, and request books from other libraries.

However, Zebulin Evelhoch (2016), an e-resource librarian from Central Washington University, one OCA member, through his analysis, noted that "the first year postmigration (2015) compared to the two years pre-migration (2013-2014) saw a decline in web page views of database (A-Z) web pages, journal full-text article requests, and database record views and result clicks. The implementation of Primo thus had a noticeable negative impact on both direct database access and overall electronic resource usage during the first year post-migration" (p16). However, for the second year and third year after golive, the access numbers were back to normal. Our study suggests that patrons need to be educated and trained to be familiar with a new discovery system during the transition of migration from a traditional OPAC.

\section{Shared Content}

Our study finds that the new shared ILS allows the consortium to continually assesse, manage, and develop initiatives that broaden access by providing cost-effective sharing, licensing, and description of such content. For example, for databases and e-journals acquisitions and subscriptions, member libraries can identify resources of interest and the Alliance works with the vendor, negotiating discounts, coordinating trials, licensing and invoicing. The OCA Electronic Resources Program is run on an opt-in/opt-out model. Subscriptions are started and purchases made when a sufficient number of libraries commit. The consortium launched its first consortial demand-driven acquisitions (DDA) e-book purchase program in 2011 facilitated by a partnership with YBP and ProQuest and funded by the consortium membership. The DDA program ended in 2017. Currently the consortium adopted the Evidence-Based Acquisitions model, partnered with Wiley and Taylor \& Francis. Another shared content project is Oxford University Press Frontlist Purchase. Our study finds the new shared ILS increases leverage in negotiations with library vendors and other system service providers. It saves labor and overhead costs by centralizing management of contractual agreements.

\section{Collaborative Technical Services}

Our study finds that OCA's Alma implementation differs from a stand-alone institution's version. According to the OCA Strategic Agenda, the OCA wanted to "manage and build the combined collections of members as one collection"; however, the shared bibliographic 
database environment still allows OCA member institutions to retain some local control and to provide a place for local order and holdings records. In order to accomplish this, Ex Libris created a three-layer system. The first layer, called the Institution Zone (IZ), houses local institutional holdings, inventory, and order records. Each OCA member institution has its own IZ. The second layer, called the Network Zone (NZ), which houses the bibliographic records of OCA's member libraries, separate but linked to the local/institutional repository (IZ) for each OCA member. While the third layer, called Community Zone (CZ), composed of e-resource records, the Alma Knowledge Base (KB), is available to all Alma users, not only for OCA members. The three-layer system made it possible and easier for OCA member institutions to work closely on collaborative technical services such as the ebook, Chinese, Japanese, and Arabic cataloging pilots. These technical services were difficult when more than 30 local ILSs were in use and workflows varied across the consortium. Thus, the shared next generation ILS opened up new opportunities and made collaboration in acquisitions, cataloging, collection development, circulation, systems, and other areas easier to achieve. It allows libraries to streamline staff operations and realize cost savings through sharing standardized bibliographic and authority records.

As a result of this type of collaboration, since the implementation of the shared ILS, the consortium members have worked together and developed a number of bibliographic records polices and shared ILS operational policies, best practices, procedures \& workflows, normalization rules, NZ account configuration \& procedures and guidelines. The consortium member libraries also share a single normalization rules for converting source records in Alma and publishing to Primo.

\section{Systems}

The maintenance and upgrades of the OCA shared ILS are centrally managed by the vendor. The cloud shared ILS lessens the necessity for each library to maintain the full complement of experts and hardware to operate their own. Our study shows that systems staff at OCA member libraries have more time to develop local applications and support customizations. The shared ILS enables sharing customization and distributed testing of new release, central monitoring, deploying and publishing. The systems staff of the OCA member institutions also collaborated on user roles management, systems authentication, systems configuration, Alma/Primo API development, primo new UI customization, resource sharing configuration, integration with other systems, etc. It enables the OCA Systems Program Manager and the Alliance Systems Team to provide centralized library automation support and services to various types of libraries in the OCA.

\section{Unique \& Local Digital Content}

Each OCA member institution has its own archival collection, institutional repository and other unique digital repositories. The new shared ILS enables the alliance to consider aggregating its member institutions' local and unique digital content. In order to achieve this goal, the OCA formed a few of working groups on archival collection, digital content metadata standards, preservation and aggregation. The OCA Council approved an AADC/DPLA proposal proposed by the Content Creation \& dissemination Team in 
February 2016. AADC stands for Aggregate Alliance Digital Content and DPLA stands for the Digital Public Library of America, a national-level portal for digital content from libraries and other cultural heritage institutions with value-added search and browse features. The AADC/DPLA project allows all Alliance members to share digital objects in Primo and DPLA. The project adheres to national standards for library automation and digitization to ensure compatibility and transferability of records and links members to regional, state, and national library networks which increase the OCA member institutions' visibility and brand awareness by providing open access to their unique and local content via the DPLA.

\section{Case Study 2 - OCUL CF Project}

OCUL is an academic library consortium of 21 university libraries in Ontario, the largest province in Canada. It has been existing for over 50 years for the collaboration and cooperation among Ontarian institutions to enhance services to students, faculty and researchers in Ontario and beyond. The collaboration activities in OCUL include group purchasing, shared digital information infrastructure, collaborative planning and professional development, etc. (Ervin-Ward and Greenberg, 2016a; OCUL, 2018a; OCUL, 2018b)

One example of shared systems is the SFX link resolver. Academic libraries in the OCUL consortium implemented a shared SFX in 2004 (Cheung, Thomas and Patrick, 2010). Each institution has its own instance while Scholars Portal maintains the central instance. Institutions relied on SFX for e-resource managing and linking for many years since then. Other innovation or collaboration based on SFX have been developed, such as the integration of SFX with Evergreen open source ILS for the unified view of print and electronic serials created by a local member, the University of Windsor, and the OCUL Usage Rights Database implemented consortially for institutions to display licensing terms on various databases to users in library catalog, journal A-Z list or other search interfaces (Liu and Zheng, 2011; Scholars Portal, 2017).

With the emergence of discovery layers and next generation ILSs, libraries in OCUL started to adopt other link resolvers or knowledge bases. It became a big burden for libraries to maintain multiple knowledge bases and link resolvers. Libraries began questioning the future of SFX and some other services offered by the consortium (ErvinWard and Greenberg, 2016a). From 2012, the OCUL Technical Advisory Group initiated discussions on cloud computing and web scale library systems across the province. A Unified Resources Management (URM) Summit was held in Toronto in February 2013. As a result, the OCUL Collaborative Approaches Task Force was established to identify potential opportunities by the new type of systems (Ervin-Ward and Greenburg, 2016b). In the meantime, one OCUL member, the University of Windsor contracted with Alma as an early adopter. University of Windsor is the first university in Ontario that selected a next generation ILS. Alma replaced several separate systems at the University, including Evergreen open source ILS, SFX and Syrup, a homegrown course reserve system (Liu, 2015).

With the efforts of the OCUL Collaborative Approaches Task Force and consultations with OCUL members, the OCUL Collaborative Futures (CF) project was 
launched in 2014. The OCUL CF project "aims to maximize the existing expertise and resources of OCUL members while fostering a deeper and more comprehensive collaborative venture among Ontario's academic libraries" (Ervin-Ward and Greenberg, 2016b, p2). More specifically, the CF project intends to implement a shared next generation ILS where members can collaborate to effectively manage electronic and print resources as well as to have a sustainable system for the management and preservation of OCUL print resources. The project consists of the following three phases:

The first phase is the feasibility study. Steering committee and several working groups were formed collaboratively to develop shared vision and collaboration framework; conduct market research, financial analysis, and business process and workflow analysis; and develop communications plan. Models of collaboration for systems, workflow and collections are also investigated. An Request for Information (RFI) was created and sent to various vendors in the market as well as companies or organizations that support open source solutions, including OCLC (MWS), Innovative Interfaces (Sierra), ProQuest (Intota), SirsiDynix (Symphony), Ex Libris (Alma), Equinox Software (Evergreen) and Kuali (Kauli OLE), etc. The findings show that most solutions are incomplete, and few products are quite mature at that time. Many can be installed in consortial environments however the level of consortial support varies dramatically. This phase completed in July 2015 (Ervin-Ward and Greenberg, 2016a; OCUL, 2018c).

The second phase is in the period of August 2015 to fall 2016. It focuses on system requirements development and procurement preparations. There are 18 institutions optedin to participate in this phase. Further investigation and planning have been conducted on the shared next generation ILSs and possible deeper collaboration among members. (OCUL, 2018b).

From winter 2017, CF enters phase three, the procurement and implementation at libraries. Thirteen institutions agreed to move forward with the shared system and another three libraries indicated continual interest with their decision forthcoming. A governance structure has been established. Four working groups were formed including Communications, Memorandum of Understanding and Governance, Requirements and Evaluation, and Shared Policy Work Group. An Expert Advisory Network was also developed to include individuals who are responsible for different areas of the OCUL CF project at local libraries. By end of 2017, an RFP has been issued for the shared system. The project team have been evaluating the responses to select a supplier. Data migration and system implementation will be following the selection. Deeper collaborations based on the shared next generation ILS are expected among participating libraries in near future (OCUL, 2018b).

In late summer of 2018, OCUL CF announced that the Alma and Primo were chosen as the solution after a long course of investigation, evaluation and negotiation. The new system is expected to be launched for all participating institutions in December 2019. Currently the consortium and its members are actively preparing for the upcoming implementation in early 2019.

It is quite challenging for such a large scope collaboration project among Ontario's academic libraries. These libraries vary a lot in terms of Full Time Equivalent (FTE) student population, library collections size and existing local ILSs. For example, in the 
consortium, York University has over 52k FTE student population while Algoma University has only about 1.2k FTE students. York University Libraries hold near 3.4 million of bibliographic records, however Algoma University Library only contains about $137 \mathrm{k}$ bibliographic records. The current systems used in the participating members spread a wide range as well, including eight different ILS solutions, four discovery layers, and a variety of institution repositories, e-reserves, learning management systems, student information systems, and financial systems across the province. The priorities and preferred timelines to move to a shared new system are quite different among these campuses. In addition, there is a mini consortium within the participating libraries, the TriUniversity Group of Libraries (TUG) (https://www.tug-libraries.on.ca/). It is a big challenge for the OCUL CF consortium to determine the cost sharing and collaboration model, and agree on various policies and workflows. This newly formed partnership articulates a number of outcomes from the shared system as follows:

- Shared records, cataloguing and electronic resource management

- Shared record loading (bibliographic records)

- Shared discovery

- Shared patron services and policies

- Shared analytics, acquisitions and collection management (University of Ottawa, 2017, p42)

The shared system will foster the deeper collaboration among Ontarian academic libraries to leverage local resources and services for users to experience "a large, diverse Ontario-wide library collection” (Ervin-Ward and Greenberg, 2016a, slide 10).

\section{CONCLUSIONS}

The next generation ILSs have been getting mature since its inception around 2011. It's been adopted by many academic libraries in the world. Academic libraries have a long history of collaboration in various activities to provide information services to students, faculty and other researchers. Due to the advancements of information technology and the budget restriction, academic libraries tend to work together on collective purchasing, shared professional development, and many other activities.

The next generation ILSs allow for deeper collaboration among libraries. The adoption data of next generation ILSs, especially Alma, indicate that more and more academic libraries are joining together to collaboratively investigate, select and implement a shared next generation ILS. Academic consortia are under different stages in moving to next generation ILSs. The case study on OCA, the pioneer adopter of Alma, reveals that a shared next generation ILS has significant impact on all aspects of library operations and services in OCA, especially in the areas of resource sharing, discovery and user experience, shared content, collaborative technical services, systems, as well as unique and local digital content. It also poses both challenges and opportunities to individual members in all these areas. The study on the OCUL CF project shows the challenges and opportunities of a shared next generation ILS to the newly formed partnership within OCUL consortium. The participating libraries are significantly different in terms of sizes, resources, services, existing systems and priorities. It is challenging for such a heterogeneous consortium to 
collaboratively move to a shared next generation ILS. However, the shared new system will foster deeper collaboration among the members to achieve their common goals.

In the future, a comprehensive investigation on all institutions who have adopted next generation ILSs would help provide a complete picture on the trends of the consortial adoption of next generation ILSs by academic libraries. Surveys and interviews on library staff from various perspectives and environments would further the understanding on the impacts, challenges and opportunities of shared next generation systems.

\section{References}

Ayre, L.B. (2015). The holy grail of library automation: The shared library system. Collaborative Librarianship, 7(1), p. 42-43.

Borgman, C.L. (1997). From acting locally to thinking globally: A brief history of library automation. The Library Quarterly: Information, Community, Policy, 67(3), p. 215249.

Bostick, S. (2001) Academic library consortia in the united states: An introduction. LIBER Quarterly, 11(1). Retrieved April 20, 2018 from https://www.researchgate.net/publication/41026158_Academic_Library_Consorti a in the United States An_Introduction

Breeding, M. (2011a). Automation marketplace 2011: the new frontier: the battle intensifies to win hearts, minds, and tech dollars. Retrieved April 20, 2018 from https://librarytechnology.org/repository/item.pl?id=15557

Breeding, M. (2011b) Current and future trends in information technologies for information units. El professional de la information, 2011, 21(1), p. 9-15.

Breeding, M. (2013) Library technology: the next generation. Computers in Libraries, 33 (8), p. 16-18. Retrieved April 20, 2018 from http://www.librarytechnology.org/ltg-displaytext.pl?RC $=18554$

Breeding, M. (2016). Introducing FOLIO - A new collaboration bringing libraries, service providers and developers together to speed innovation and redefine the future of library automation. Retrieved April 20, 2018 from https://librarytechnology.org/pr/21713

Breeding, M. (2017a) Development timeline for library services platforms. Library Technology Guides. Retrieved April 20, 2018 from https://librarytechnology.org/chron/libraryservicesplatforms.pl

Breeding, M. (2017b). Library Systems Report 2017: competing visions for technology, openness, and workflow. American Libraries, May 1, 2017. Retrieved April 20, 2018 from https://americanlibrariesmagazine.org/2017/05/01/library-systemsreport-2017/.

Breeding, M. (2018a). Integrated library system turnover in 2017. Retrieved April 20, 2018 from https://librarytechnology.org/ils-turnover.pl?Type=Academic \&Year=2017

Breeding, M. (2018b) Perceptions 2017: An international survey of library automation. Retrieved April 20, 2018 from https://librarytechnology.org/perceptions/2017/

Breeding, M. (2018c) Product installation statistics. Retrieved April 14, 2018 from https://librarytechnology.org/product-installation-statistics.pl

Breeding, M. (2018d) Survey response demographics for 2017. Available April 14, 2018 from https://librarytechnology.org/perceptions/2017/demographics.pl 
Chan, L.H. and Lam, K.T. (2016) Eight universities in Hong Kong are moving to next generation integrated library systems: A shared ILS for JULAC, in Academic Libraries Trends and Services Innovation Forum, April 14, 2016, Xian, China. [in Chinese]

Cheung, O., Thomas, D. and Patrick, S. (2010) New approaches to e-Reserve, linking, sharing and streaming. Chandos Publishing, Cambridge, UK.

Cornish, A., Jost, R. and Arch, X. (2013) Selecting a shared 21st century management system. Collaborative Librarianship, 5(1), Article 3. Retrieved April 20, 2018 from https://digitalcommons.du.edu/collaborativelibrarianship/vol5/iss1/3

Cote, C. and Ostergaard, K. (2017) Master of "complex and ambiguous phenomena": The ERL's role in a library service platform migration. The Serials Librarian, 72(1-4), p. 223-229. DOI: 10.1080/0361526X.2017.1285128

Davis, D. M. (2007). Library networks, cooperatives and consortia: A national survey, ALA Report (December 3, 2007), Retrieved April 20, 2018 from https://www.google.ca/url?sa=t\&rct=j\&q=\&esrc=s\&source=web\&cd=2\&ved=0a hUKEwjvvLju363aAhVSYK0KHbCFBnsQFggtMAE\&url=https\%3A\%2F\%2Fw ww.webjunction.org\%2Fcontent $\% 2$ Fdam $\% 2$ FWebJunction $\% 2$ FDocuments $\% 2 \mathrm{Fp}$ ennsylvania\%2FLibraryConsortia_National\%2520Summary_ALA.pdf.doc\&usg= AOvVaw1Z2hrcVIycdkBagDayqPJZ

Deng, S., Sotelo, A. and Culbertson, R. (2018) Cataloging for consortial collections: A survey. Cataloging \& Classification Quarterly, 56(2-3), p. 171-187, DOI: 10.1080/01639374.2017.1388327

Ervin-Ward, A. and Greenberg, A. (2016a) Collaborating for the future: A consortial approach to next generation library systems, in Library Technology Conference 2016, March 16-17, 2016, St. Paul, MN.

Ervin-Ward, A. and Greenberg, A. (2016b) Fostering radical collaboration: The OCUL collaborative futures project. Partnership, 11(1). Retrieved April 20, 2018 from http://dx.doi.org/10.21083/partnership.v11i1.3633

Evelhoch, Z. (2016). Web-scale discovery: Impact on library database web page views and usage. Journal of Web Librarianship 10(3), 197-209. DOI: 10.1080/19322909.2016.1191048

Fu, P. (2017) Impact of next generation ILS on the U.S. library consortia: An analysis. Digital Library Forum, 153, p.27-33. DOI : 10.3772/j.issn.1673-2286.2017.2.005 [in Chinese]

Grant, C. (2012). The future of library systems: Library services platforms. Information Standards Quarterly, 24(4), p.4-15.

Helmer, J.F., Bosch, S., Sugnet, C. and Tucker, J.C. (2012) Innovation through collaboration - the Orbis Cascade Alliance experience: an interview with John F. Helmer, Collaborative Librarianship, 4(4), p.183-185.

Horton, V. (2012a). The collaborative shift has happened. Collaborative Librarianship, 4(4), p. 130-131.

Horton, V. (2012b). Trends in library collaboration: Deeper, wider, and riskier. Collaborative Librarianship, 4(2), p. 38.

Horton, V. (2015). Library consortia overview. Chapter 1 in Library Consortia: Models for Collaboration and Sustainability. Horton, V. and Pronevitz, G. (Eds.) American Library Association: Chicago, IL. 
Kopp, J.J. (1998) Library consortia and information technology: The past, the present, the promise. Information Technology and Libraries, 17(1), p7-18

Lam, K.T. (2017) The birth of the JULAC shared integrated library system process and prospect, in Library Collaboration at Dizzying Heights: Innovation and Impact, JULAC 50 ${ }^{\text {th }}$ Anniversary Conference. December 5-6, 2017, Hong Kong.

Liu, G. (2015). Library resources management system in the age of cloud computing. Journal of Baoshan University, 34 (3), p. 28-32. [in Chinese]

Liu, G. and Zheng, H. (2011) Access to serials: integrating SFX with Evergreen open source ILS. Library Hi Tech, 29(1), p.137-148. https://doi.org/10.1108/07378831111116967

Machovec, G. (2014) Consortia and next generation integrated library systems. Journal of Library Administration, 54(5), p.435-443. DOI: 10.1080/01930826.2014.946789

McKiel, A. and Dooley, J. (2014). Changing library operations: consortial demand-driven eBooks at the University of California. Against the Grain, 26(3), p. 59-61. Retrieved November 21, 2018 from https://docs.lib.purdue.edu/cgi/viewcontent.cgi? article=6771\&context=atg.

Mfengu, A.Y. (2014). Analysis of the approaches of senior management teams towards adoption of next generation library management systems: Case study of Cape library consortium institutions (Master's thesis). Retrieved April 20, 2108 from https://open.uct.ac.za/handle/11427/13734.

OCLC (2013). A snapshot of priorities \& perspectives: U.S. library consortia. Retrieved April 20, 2018 from https://www.oclc.org/en/reports/us-consortia.html

Ontario Council of University Libraries (OCUL). (2018a) About OCUL. Retrieved April 20, 2018 from https://ocul.on.ca/about

OCUL. (2018b) A history of collaboration. Retrieved April 20, 2018 from https://ocul.on.ca/history

OCUL. (2018c) OCUL Collaborative Futures. Retrieved April 20, 2018 from https://ocul.on.ca/projects/collaborative-futures.

Potter, W.G. (1997) Recent trends in statewide academic library consortia. Library Trends, 45(3), p. 416-434.

ProQuest. (2018) Alma and Primo Expand Regional Presence with Adoption by Two Leading Japanese Institutions, Keio University and Waseda University. TOKYO, JAPAN, March 28, 2018. Press releases. Retrieved April 20, 2018 from http://www.proquest.com/about/news/2018/Alma-and-Primo-Expand-RegionalPresence-with-Leading-Japanese.html

Romaine, S. and Wang, J. (2017) When ERM Met Alma: The Intricacies of Content Management in a Shared Consortia Landscape, Serials Review, 43:1, 17-27. DOI: $10.1080 / 00987913.2017 .1279896$

Rosa, K. and Storey, T. (2016). American libraries in 2016: creating their future by connecting, collaborating and building community. International Federation of Library Associations and Institutions, 42(2), p. 85-101. DOI: 10.1177/0340035216646061

Scholars Portal. (2017) OUR - OCUL Usage Rights Database. Retrieved April 20, 2018 from http://guides.scholarsportal.info/our

Shadle, S. and Davis, S. (2016) Wrangling cats: A case study of a library consortium 
migration. The Serials Librarian, 70(1-4), p.116-120, DOI: 10.1080/0361526X.2016.1148421

Spring, K., Campbell, D., Drost, C. and Romaine, S. (2015) How is that going to work? Part II - Acquisitions challenges and opportunities in a shared ILS. Faculty \& Staff Publications. Published Version. Submission 13. Retrieved April 20, 2018 from http://digitalcommons.linfield.edu/librariesfac_pubs/13

Spring, K., Drake, M. and Romaine, S. (2014) How is that going to work? Rethinking acquisitions in a next-generation ILS. Faculty \& Staff Publications. Published Version. Submission 11. Retrieved April 20, 2018 from http://digitalcommons.linfield.edu/librariesfac_pubs/11

Stewart, M. and Morrison, C.A. (2016). Consortial migration to a next-generation ILS and its impact on acquisitions workflows. LRTS 60(4), p. 259-269

University of Ottawa. (2017) Request for Proposals (RFP) Software as a Service (SaaS) Library Services Platform. Retrieved April 20, 2018 from https://ocul.on.ca/sites/default/files/2017052-RFP_for_LSP_28-Nov2017_Final_0.pdf

Wilson, K. (2012) Introducing the next generation of library management systems. Serials Review, 38, p. 110-123.

Zhu, L. and Spidal, D.F. (2015) Shared integrated library system migration from a technical services perspective. Technical Services Quarterly, 32:3, 253-273.

DOI: $10.1080 / 07317131.2015 .1029844$

\section{About the authors}

Guoying Liu is Librarian, Head of Systems at Leddy Library, University of Windsor.

Ping Fu is Professor and Head of Library Technology Services in the Brooks Library at Central Washington University. 